\title{
Modeling and Forecasting Under-Five Mortality Rate in Nigeria using Auto-Regressive Integrated Moving Average Approach
}

\author{
Donalben Onome Eke and Friday Ewere
}

\begin{abstract}
Nigeria's efforts aimed at reducing avoidable child deaths have been met with gradual and sustained progress. Despite the decline in childhood mortality in Nigeria in the last two decades, its prevalence still remain high in comparison to the global standard of mortality for children under the age of five which stands at 25 deaths per 1000 live births. Knowledge of the chances of Nigeria achieving this goal for childhood mortality will aid proper interventions needed to reduce the occurrence.

Therefore, this paper employed the Auto-Regressive Integrated Moving Average (ARIMA) model for time series analysis to make forecast of under-five mortality in Nigeria up to 2030 using data obtained from the United Nation's Inter Agency Group for Childhood Mortality Estimate (UN-IGME).

The ARIMA $(2,1,1)$ model predicted a reduction of up to $37.3 \%$ by 2030 at $95 \%$ confidence interval. Results from the study also showed that a reduction of over $300 \%$ in under-five mortality is required for Nigeria to be able to achieve the SDG goal for underfive mortality.
\end{abstract}

\section{Introduction}

Under-five mortality rate defined as the probability of a child who survives to age one dying between age one and five in a given year for a particular geographical location [13], [8] has long been identified as a barometer for the measurement of a country's state of health and health care facilities as well as one of the fundamental tools for the evaluation of a country's level of social economic development. It is therefore an

Received: May 19, 2020; Accepted: June 15, 2020

2010 Mathematics Subject Classification: 62.

Keywords and phrases: ARIMA model, time series forecasting, under-five mortality, Nigeria.

Copyright $\odot 2020$ Authors 
important public health challenge requiring urgent attention. As a result, relevant stake holders in public health and government moved to curb its rate of occurrence by adopting a systematic approach to reducing under-five deaths by two thirds between 1990 and 2015 as contained in the fourth tenet of the Millennium Development Goals (MDG) 4, [5].

While many countries in Europe and America experienced rapid decline in the rate of under-five mortality sufficient enough to meet the childhood mortality target as spelt out in the Millennium Development Goal 4, countries in Sub Saharan Africa still maintained relatively high mortality rates [6]. Whilst there was a steady reduction in under five deaths in Nigeria between 1990 and 2015, mortality still remained relatively and unacceptably high [4], [2] leading to Nigeria's inability to attain the MDG 4 target.

The failure of many countries in Africa (including Nigeria) to attain the Millennium Development Goals for childhood mortality led to the birthing of the Sustainable Development Goal (SDG) for the reduction of childhood death among other targets. Studies conducted after the kickoff of SDG indicates that Nigeria still experience high under-five mortality. According to a report by Multiple Indicator Cluster Survey (MICS5) in 2017, one in 9 live births die before their fifth birth day in Nigeria. The current rate of under-five mortality in Nigeria which is 120 per 1,000 live births [11] is still unacceptably high and puts the country at great risk of falling short of the SDG for childhood mortality as well as paints the general state of health care facilities in the country in bad light.

Studies have focused on the significant predictors of under-five mortality [1], levels and trends of under-five mortality [7], and prevalence and determinants of childhood mortality [14]. Whilst the results of these studies have been useful in helping to identify significant determinants of under-five mortality as well as to identify the major causes of under-five death, it appears there has been a neglect of studies focused on monitoring the progress of under-five mortality in Nigeria with a view to determining the chances of attaining the SDG target for childhood mortality.

The importance of the knowledge of future mortality rate forecasting to decision makers in the public health sector in Nigeria and the world over cannot be overemphasized. Hence, this paper is both timely and instrumental to the analysis of under-five mortality aimed at determining the chances of Nigeria attaining the SDG target of childhood mortality in Nigeria. 
The incidence of neonatal mortality in Nigeria between 1990 and 2017 using ARIMA techniques of time series to make forecast had been examined by [12]. Also, the decrease in under-five mortality rate in Ghana using a combination of ARIMA models and the Bayesian Dynamic Linear Model, along with the Random walk with drift models had been employed by [9] to successfully make forecast of under-five mortality rate in Ghana.

\section{Methods}

Study Area: This paper is focused on Nigeria. Nigeria is made up of 36 states and a Federal Capital Territory (FCT), grouped into six geopolitical zones; North Central, North-East, North-West, South-East, South-South, and South-West.

Data Source: This study is conducted using data obtained from the World Bank Group [11].

Data Analysis: Analysis of the data for under-five mortality rate in Nigeria was done using the SPSS software version 22. The ARIMA modeling technique in time series analysis was adopted to make forecast. A three step algorithm of model identification, estimation and diagnostic checking before making a forecast had been proposed by [3]. However, this requires that the series is stationary. Stationary time series data do not usually exhibit any trend (upwards or downwards). Forecast of the mortality rate for children under five years of age in Nigeria was carried out at $95 \%$ confidence interval using the ARIMA model.

\section{Results and Discussion}

Table 1. Estimates of under-five mortality rates between 1960 and 2018.

\begin{tabular}{|c|c|c|c|c|c|c|c|c|}
\hline S/N & Year & $\begin{array}{c}\text { Under-Five } \\
\text { mortality }\end{array}$ & S/N & Year & $\begin{array}{c}\text { Under- } \\
\text { Five } \\
\text { mortality }\end{array}$ & S/N & $\begin{array}{c}\text { Under- } \\
\text { Five } \\
\text { mortality }\end{array}$ \\
\hline 1 & 1960 & 351 & 21 & 1980 & 213 & 41 & 2000 & 185 \\
\hline 2 & 1961 & 347 & 22 & 1981 & 210 & 42 & 2001 & 156 \\
\hline 3 & 1962 & 341 & 23 & 1982 & 208 & 43 & 2002 & 151 \\
\hline 4 & 1963 & 335 & 24 & 1983 & 208 & 44 & 2003 & 146 \\
\hline 5 & 1964 & 327 & 25 & 1984 & 208 & 45 & 2004 & 142 \\
\hline 6 & 1965 & 320 & 26 & 1985 & 208 & 46 & 2005 & 138 \\
\hline 7 & 1966 & 314 & 27 & 1986 & 209 & 47 & 2006 & 135 \\
\hline
\end{tabular}




\begin{tabular}{|c|c|c|c|c|c|c|c|c|}
\hline 8 & 1967 & 307 & 28 & 1987 & 210 & 48 & 2007 & 133 \\
\hline 9 & 1968 & 300 & 29 & 1988 & 211 & 49 & 2008 & 131 \\
\hline 10 & 1969 & 293 & 30 & 1989 & 211 & 50 & 2009 & 129 \\
\hline 11 & 1970 & 285 & 31 & 1990 & 211 & 51 & 2010 & 127 \\
\hline 12 & 1971 & 277 & 32 & 1991 & 211 & 52 & 2011 & 125 \\
\hline 13 & 1972 & 269 & 33 & 1992 & 210 & 53 & 2012 & 124 \\
\hline 14 & 1973 & 260 & 34 & 1993 & 209 & 54 & 2013 & 122 \\
\hline 15 & 1974 & 252 & 35 & 1994 & 208 & 55 & 2014 & 120 \\
\hline 16 & 1975 & 244 & 36 & 1995 & 206 & 56 & 2015 & 156 \\
\hline 17 & 1976 & 236 & 37 & 1996 & 203 & 57 & 2016 & 151 \\
\hline 18 & 1977 & 229 & 38 & 1997 & 200 & 58 & 2017 & 146 \\
\hline 19 & 1978 & 223 & 39 & 1998 & 195 & 59 & 2018 & 142 \\
\hline 20 & 1979 & 218 & 40 & 1999 & 190 & & & \\
\hline \multicolumn{2}{|l|}{ Source: world bank, www.childmortality.org } \\
\hline
\end{tabular}

The data contained in Table 1 is an estimate of the under-five mortality rate for Nigeria per 1000 live births between 1960 and 2018.

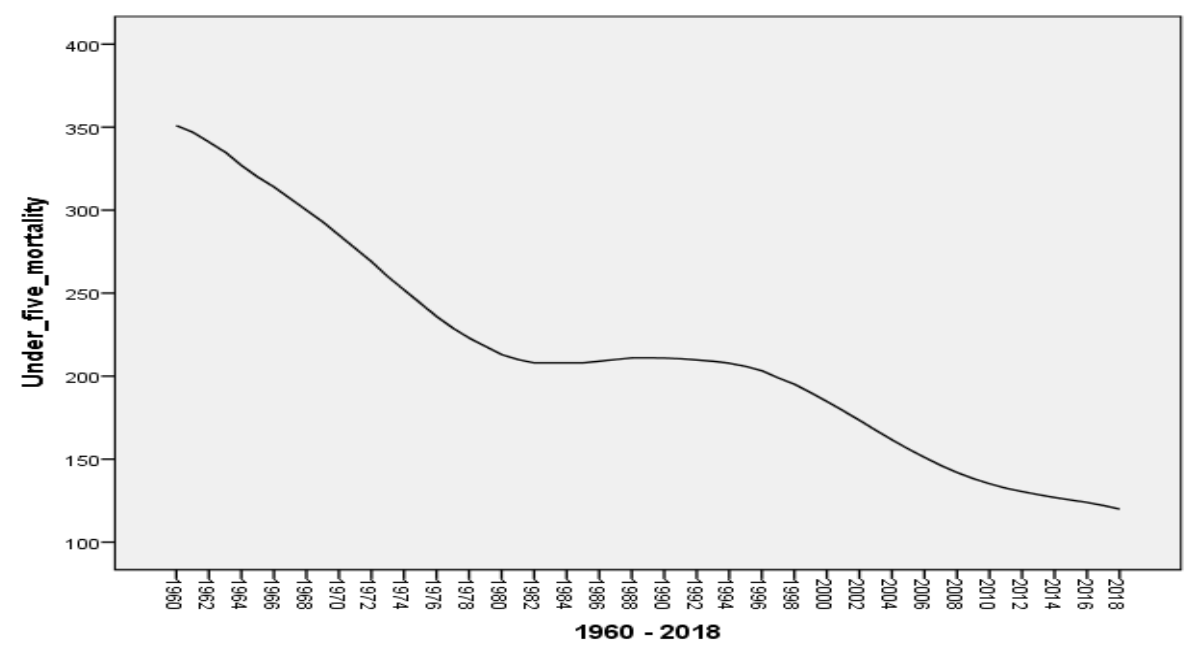

Figure 1. A time plot of under-five mortality series from 1960 to 2018.

A visual inspection of the time series plot of under-five mortality in Figure 1 shows clearly that the data is not stationary. The plot shows that there is a decreasing trend in the time series. In order to stabilize the variance and make the time series stationary, the series is transformed by $W_{t}=\Delta y_{t}-y_{t-1}$. That is, the first order difference of the time series data was computed. After taking the first difference, the differenced series has $n-1$ observations. Figure 2 provides the plot of the resulting differenced time series. 


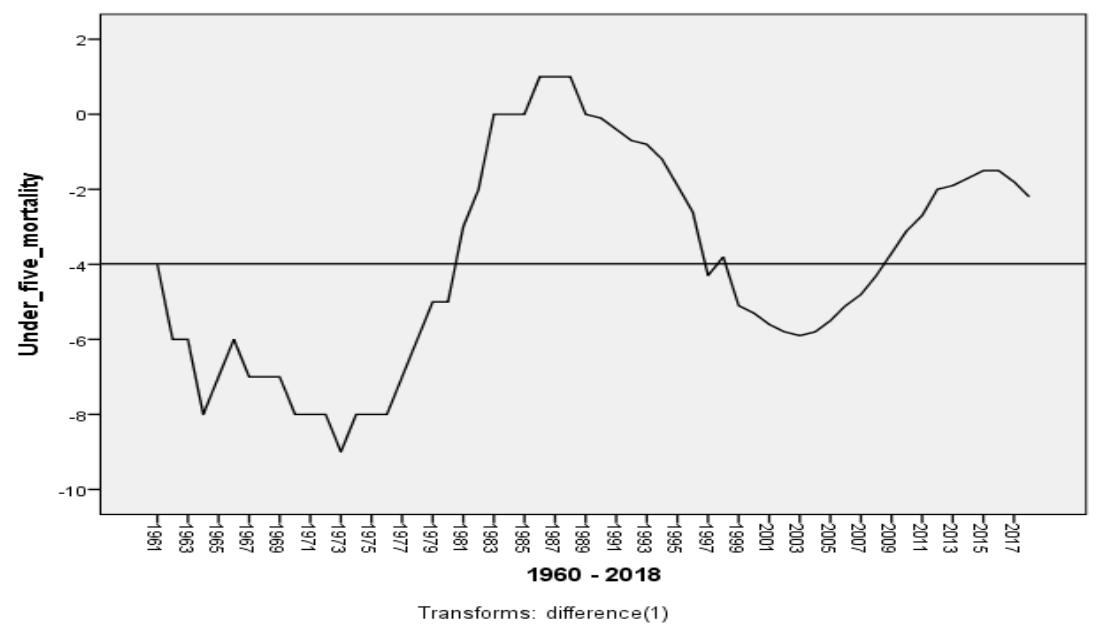

Figure 2. Time series plot of the first difference $(d=1)$.

A look at the time series plot of the differenced series in Figure 2 shows that the time series appears stationary and devoid of trend. In this case, the mean and the variance now seem consistent over time compared to the plot in Figure 1.

Table 2. Augmented Dickey-Fuller tests.

\begin{tabular}{c|c|c|c} 
Dickey-Fuller & Sig. & $\begin{array}{c}\text { ACF coeff. of } e \\
(d=1)\end{array}$ & DF \\
\hline-3.264 & 0.048 & 0.128 & 16
\end{tabular}

Also, we apply the unit root test otherwise known as the Augmented Dickey-Fuller test. The unit root test used for testing for stationarity proposes that if $\phi_{1}=1$ in the simple autoregressive scheme $Z_{t}=\mu+\phi_{1} Z_{t-1}+\varepsilon_{t}$, where $\phi_{1}$ is the coefficient of the auto-regression process, then the series is said to possess a unit root and is thus not stationary. This is because it violates the basic requirement of zero mean and constant variance necessary for time series modeling.

To test for stationarity in the time series data, we adopt the following hypothesis:

$H_{0}:$ the series contains a unit root

$H_{1}:$ there is no unit root in the series

The null hypothesis is rejected and the alternative hypothesis is true implying that the series is stationary if the p-value is greater than the significance level: $\alpha=0.01$. 
Since the computed $\mathrm{p}$-value $=0.048$ in Table 2 is greater than $\alpha=0.01$ we reject the null hypothesis and conclude that the series is stationary after taking the first difference $(d=1)$.

Table 3. Autocorrelation and partial autocorrelation of the series.

\begin{tabular}{|c|c|c|c|c|}
\hline Lag & Autocorrelation & Std. Error & $\begin{array}{c}\text { Partial } \\
\text { Autocorrelation }\end{array}$ & $\begin{array}{c}\text { Std. } \\
\text { Error }\end{array}$ \\
\hline 1 & .957 & .128 & .957 & .131 \\
2 & .900 & .127 & -.195 & .131 \\
3 & .811 & .126 & -.384 & .131 \\
4 & .700 & .125 & -.281 & .131 \\
5 & .579 & .123 & -.052 & .131 \\
6 & .441 & .122 & -.166 & .131 \\
7 & .297 & .121 & -.132 & .131 \\
8 & .156 & .120 & .032 & .131 \\
9 & .020 & .119 & .012 & .131 \\
10 & -.114 & .117 & -.162 & .131 \\
11 & -.227 & .116 & .081 & .131 \\
12 & -.324 & .115 & .081 & .131 \\
13 & -.407 & .114 & -.113 & .131 \\
14 & -.466 & .112 & .003 & .131 \\
15 & -.499 & .111 & .179 & .131 \\
16 & -.511 & .110 & .010 & .131 \\
17 & -.501 & .109 & -.114 & .131 \\
18 & -.477 & .107 & -.018 & .131 \\
19 & -.437 & .106 & .039 & .131 \\
20 & -.374 & .104 & .109 & .131 \\
21 & -.305 & .103 & -.049 & .131 \\
22 & -.224 & .102 & .054 & .131 \\
23 & -.147 & .100 & -.136 & .131 \\
24 & -.070 & .099 & -.068 & .131 \\
\hline
\end{tabular}

Figure 3 displays the Auto Correlation Function (ACF) from lags 1 to 24 of the first order differenced time series of under-five mortality rate in Nigeria. Figure 3 shows that the ACF dies down to zero slowly as the number of time lags $\mathrm{k}$ increases indicating a geometric decay symbolic of an AR process. 


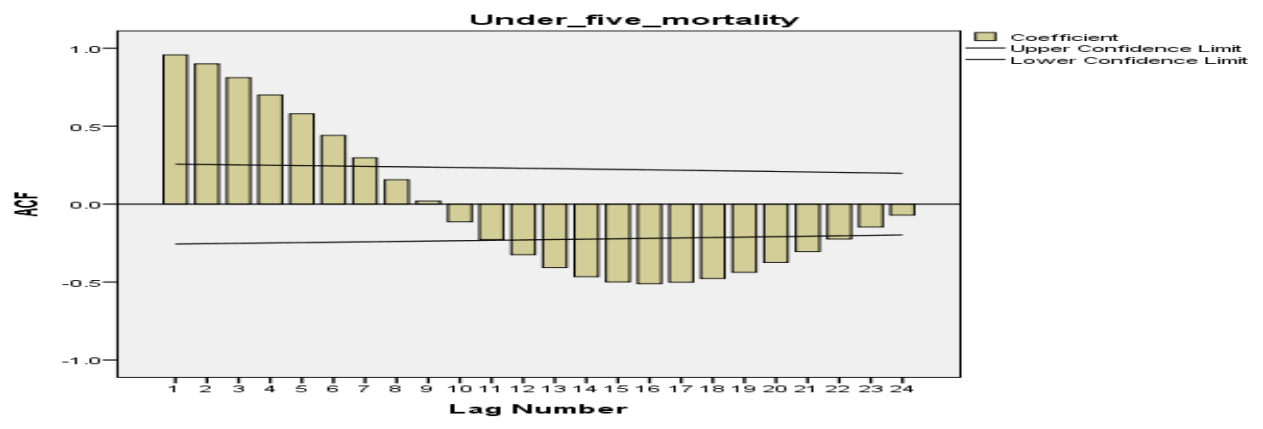

Figure 3. ACF for under-five mortality.

Figure 4 is the Partial Auto Correlation Function (PACF) for under-five mortality in Nigeria. The PACF shows that there are only two significant time lags. Only time lags 1 and 3 exceeds the significant threshold which is the error bound indicating an AR (2) model. All other time lags fall within the significant threshold.

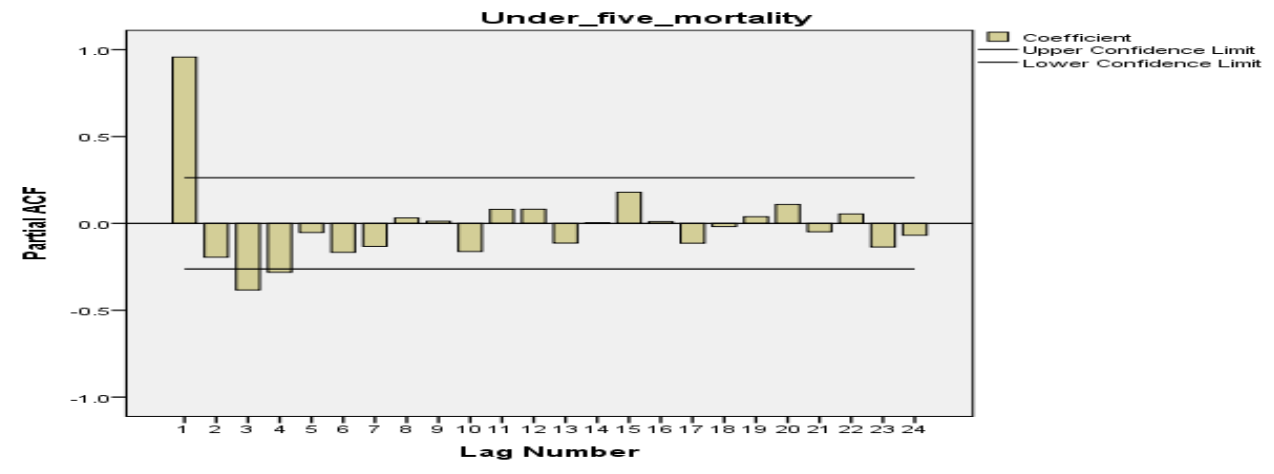

Figure 4. PACF for under-five mortality.

Having identified the theoretical properties of the ACF and PACF as an AR (2) process given that the ACF of the differenced series dies down to zero slowly and the dying down pattern produced by the AR component, dominate the cutting of pattern produced by the Moving Average (MA) component, then we infer that the ARIMA model is either an ARIMA $(2,1,1),(2,1,0),(1,1,0)$ or $(1,1,1)$ if the decision is to consider one time lag of the error term.

Table 4 presents the tentative models identified based on the principle of parsimony and recognizable pattern of the ACF and PACF. The best approximation to the data by the member of ARIMA family is obtained by comparing the Alkaike Information Criterion (AIC) and Bayesian Information Criterion (BIC) values. 
Table 4. Possible fitted ARIMA model for under-five mortality rate in Nigeria.

\begin{tabular}{|c|c|c|}
\hline Models & AIC & BIC \\
\hline ARIMA (1, 1, 0) & 23.34 & 25.77 \\
\hline ARIMA (1, 1, 1) & 23.16 & 24.91 \\
\hline ARIMA (2, 1, 1) & 23.43 & 23.10 \\
\hline ARIMA (1, 1, 2) & 23.84 & 23.61 \\
\hline ARIMA (2, 1, 0) & 25.45 & 26.91 \\
\hline
\end{tabular}

A comparison of the AIC and the BIC values for the possible models shows that ARIMA $(1,1,1)$ has the least AIC value. However, the ARIMA $(2,1,1)$ produced least values for both the AIC and the BIC and is therefore selected as the best fit model for the data.

Table 5. Estimated summary for the ARIMA $(2,1,1)$ model.

\begin{tabular}{|c|c|c|c|c|c|}
\hline \multirow{2}{*}{} & \multicolumn{5}{|c|}{ ARIMA Model Parameters } \\
\cline { 2 - 4 } & \multicolumn{5}{|c|}{ Under_five_Mortality-Model_1 } \\
\cline { 2 - 4 } & \multicolumn{5}{|c|}{ No Transformation } \\
\cline { 2 - 6 } & \multirow{3}{|c|}{ AR } & MA \\
\cline { 2 - 6 } & Constant & Lag 1 & Lag 2 & Difference & Lag 1 \\
\cline { 2 - 6 } Estimate & -3.585 & .205 & .702 & 1 & -.902 \\
SE & 1.677 & .194 & .191 & & .131 \\
$\mathrm{t}$ & -2.138 & 1.060 & 3.677 & & -6.880 \\
Sig. & .037 & .294 & .001 & & .000 \\
\hline
\end{tabular}

The ARIMA $(2,1,1)$ model for under-five mortality in Nigeria is thus given as

$$
Z_{t}=\mu+Z_{t-1}+\phi_{1} Z_{t-1}+\phi_{2} Z_{t-2}-\theta_{1} \varepsilon_{t-1}
$$

that is,

$$
Z_{t}=-3.585+Z_{t-1}+0.205 Z_{t-1}+0.702 Z_{t-2}-0.902 \varepsilon_{t-1},
$$

where $Z_{t}$ is the stationary series observed, $\mu$ is the mean of the time series (constant), $\phi_{i}$ and $\theta_{1}$ are the parameter estimates and $\varepsilon_{t}$ is the white noise with zero mean and constant variance.

The residual ACF and PACF plots are used to check the adequacy of the model as a good fit of the time series data before it is used for forecast. 
The diagnostics of the residuals by the ACF and PACF in Figure 5 clearly shows that their values are all within the $5 \%$ zero bound indicating that there is no correlation amongst the residuals. This plot is used as an indicator of the independence of the residual terms.

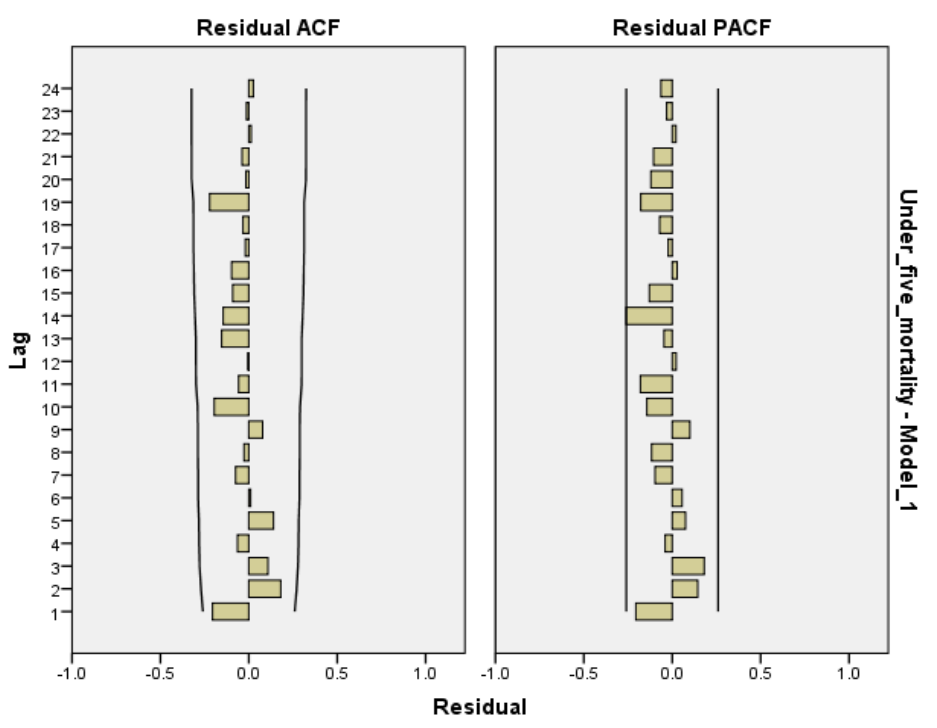

Figure 5. Residual ACF and PACF plot.

A look at the plot of the residual ACF in Figure 5 shows that all the values of the autocorrelation coefficients between lags 1 and 24 are within the $5 \%$ zero bound.

Similarly, all the PACFs coefficients of the residuals of the fitted ARIMA $(2,1,1)$ model for lags 1 to 24 are within the significant limits. This means ACF and PACF concluded that there is no non-zero autocorrelations in the residuals.

The Ljung-Box test results are shown in Table 6 while Figure 6 represents the plot of the standard residual for the fitted model:

Table 6. Ljung-Box test statistics.

\begin{tabular}{|c|c|c|c|c|c|}
\hline \multirow{2}{*}{ Model } & $\begin{array}{c}\text { Model Fit } \\
\text { statistics }\end{array}$ & \multicolumn{3}{|c|}{ Ljung-Box Q(18) } & \multirow{2}{*}{$\begin{array}{c}\text { Number of } \\
\text { Outliers }\end{array}$} \\
\cline { 2 - 5 } & $\begin{array}{c}\text { Stationary } \\
\text { R-squared }\end{array}$ & Statistics & DF & Sig. & \\
\hline Under-five Mortality & .112 & 15.612 & 16 & .048 & 0 \\
\hline
\end{tabular}




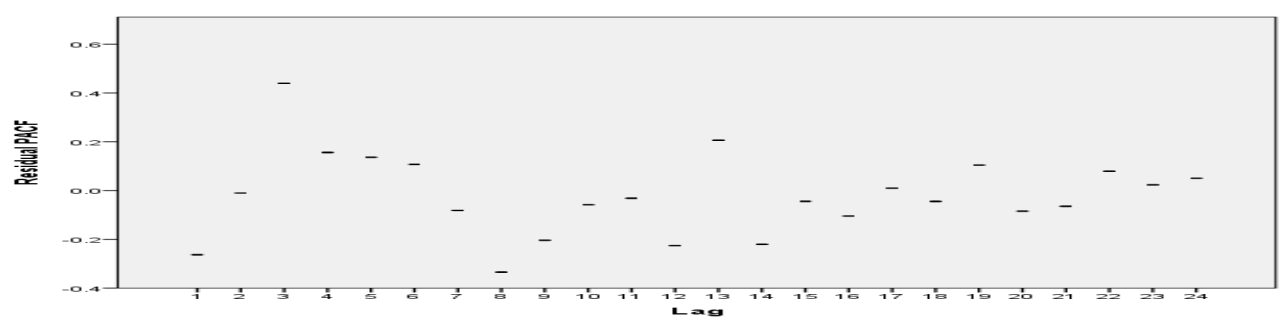

Figure 6. Standard residual for the fitted ARIMA model.

The statistics and a P-value of 0.048 in Table 6 shows that all of the autocorrelation functions in lags 1 to 24 are either zero or close to zero. The inference here is that there is no (or almost no) evidence for non-zero autocorrelations in the residuals at lags 1 to 24 in the fitted model.

Hence, the ARIMA $(2,1,1)$ model chosen is fitted to forecast for the future values of the time series.

The K period ahead forecast based on the $\operatorname{ARIMA}(2,1,1)$ model is given by

$$
\hat{Z}_{t+k}=\mu+Z_{t+k-1}+\phi_{1} Z_{t+k-1}+\phi_{2} Z_{t+k-2}-\theta_{1} \varepsilon_{t+k-1},
$$

where

$$
\begin{aligned}
& \mu=-3.585, \phi_{1}=0.201, \phi_{2}=0.702, \theta_{1}=-0.902 \\
& \hat{Z}_{t+k}=-3.585+Z_{t+k-1}+0.205 Z_{t+k-1}+0.702 Z_{t+k-2}+0.902 \varepsilon_{t+k-1} .
\end{aligned}
$$

After fitting the ARIMA $(2,1,1)$ model to forecast for the future values of mortality in children under five years of age up to year 2030, we obtained the following forecast estimates as given in Table 7.

Table 7 shows the forecast for under-five mortality rate in Nigeria for 2019 through to 2030 with $95 \%$ upper and lower confidence intervals. Results from the childhood mortality forecast shows that there will be a $37.3 \%$ reduction in the occurrence of mortality in children under five years of age by 2030 which is an annual reduction of $3.1 \%$.

Figure 7 below shows the plot of the observed series from 1960 to 2018 and the forecast for 2019 up to year 2030 of under-five mortality by fitting the ARIMA $(2,1,1)$ model to the time series data. 
Table 7. Forecast of under-five mortality rate in Nigeria.

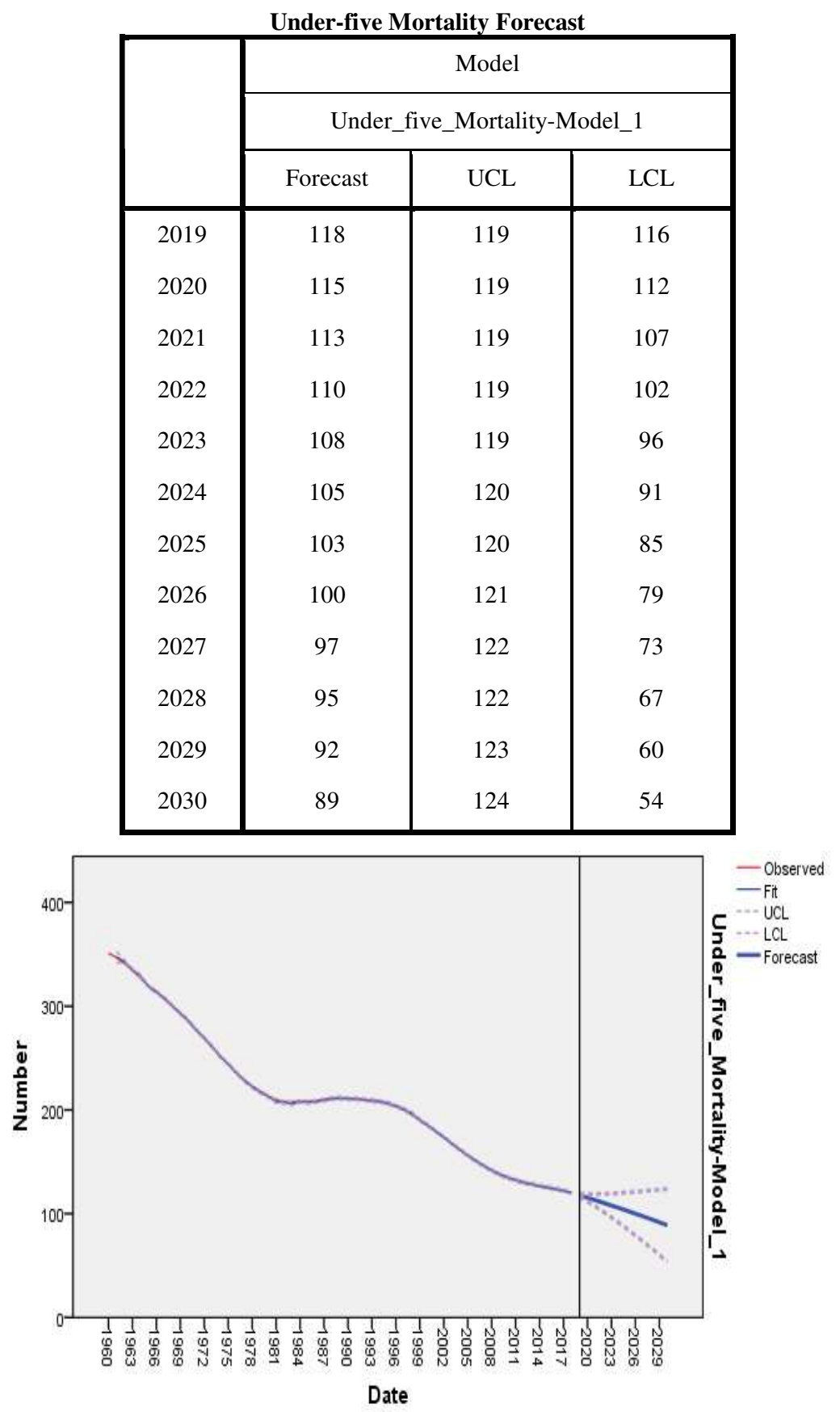

Figure 7. Plot of the observed series and the in-sample forecast value. 
The portion of the plot from the year 2019 to 2030 shows the in - sample estimated and forecast values of under-five mortality rate in Nigeria by the ARIMA $(2,1,1)$ model produced from the data with the $95 \%$ Confidence Interval for each of the forecast value, depicted by the two opening lines.

The forecast estimate in Table 7 shows that by 2030, Nigeria will have a reduced mortality rate of 89 deaths per 1,000 live births for under-five mortality. Whilst this would be an improvement compared to previous mortality rates, it would still fall significantly short of the global target for childhood mortality.

To meet the recommended set target for the mortality of children under five years of age in Nigeria as proposed by the United Nations in the sustainable development goal by 2030 , the country would have to experience a reduction of over $300 \%$.

\section{Conclusion}

This paper used data estimates from the United Nation's Inter Agency Group for Childhood Mortality Estimates (UN IGME) obtained from World Bank to model and make forecast of under-five mortality rate in Nigeria.

The ARIMA $(2,1,1)$ model was applied to make forecast for under-five mortality rate in Nigeria for the years 2019 through 2030. The time plot of the forecast from the ARIMA $(2,1,1)$ model showed a downward movement suggesting that there would be a continuous decrease in under-five mortality rate. The ARIMA $(2,1,1)$ model predicted a reduction of up to $37.3 \%$ by 2030 at $95 \%$ confidence interval. Despite this reduction, Nigeria is set to fall short of the Sustainable Development Goal for childhood mortality by 2030 . In order to significantly combat childhood mortality occurring within the first five years of life and attain the target of 25 deaths per 1,000 live births as proposed by SDG by the year 2030, it is recommended that there should be concerted efforts at all levels of government to put in place highly effective immunization programmes for children. Children who are immunized have stronger resistance to sickness and diseases. Also, government should engage in constant enlightenment of parents particularly women on the need to step up cultural practices within their power to end preventable child death. Simple practices such as constant hand washing, boiling of water before drinking and use of contraceptives to ensure proper spacing of births according to recommended standards of the Safe Motherhood Initiative [10] can go a long way to prevent diseases such as diarrhea and cholera as well as reduce death caused by 
complications of inadequate birth spacing. The use of mosquito nets by households should also be encouraged to prevent under-five mortality via malaria.

\section{Acknowledgement}

The authors would like to thank the World Bank Group and the United Nation InterAgency Group for Childhood Mortality Estimation (UN-IGME) for access to the data set used for the analysis.

\section{References}

[1] G. W. Adetoro and E. O. Amoo, A statistical analysis of child mortality: Evidence from Nigeria, Journal of Demography and Social Statistics 1 (2014), 110-120.

[2] O. Aremu, S. Lawoko and K. Dalal, Neighbourhood socioeconomic disadvantage, individual wealth status and patterns of delivery care utilization in Nigeria: a multilevel discrete choice analysis, Int. Journal of Women's Health 3 (2011), 167-174. https://doi.org/10.2147/IJWH.S21783

[3] G. E. P. Box and G. M. Jenkins, Time Series Analysis, Forecasting and Control, HoldenDay, Oakland, CA, 1976.

[4] V. T. Adekanmbi, G. A. Kayode and O. A. Uthman, Individual and contextual factors associated with childhood stunting in Nigeria: a multilevel analysis, Maternal Child Nutr. 9(2) (2013), 244-259. https://doi.org/10.1111/j.1740-8709.2011.00361.x

[5] J. Fox, Public health, poor relief and improving urban child mortality outcomes in the decade prior to the New Deal, MPIDR Working Paper WP-2011-005, 2012. https://doi.org/10.4054/MPIDR-WP-2011-005

[6] G. Mesike and N. Mojekwu, Environmental determinants of child mortality in Nigeria, Journal of Sustainable Development 5(1) (2012). https://doi.org/10.5539/jsd.v5n1p65

[7] O. M. Morakinyo and A. F Fagbamigbe, Neonatal, infant and under-five mortalities in Nigeria: an examination of trends and drivers (2003-2013), PLOS ONE 12(8) (2017), e0182990. https://doi.org/10.1371/journal.pone.0182990

[8] National Population Commission and ICF Macro, Nigerian Demographic and Health Survey 2008, National Population Commission, Federal Republic of Nigeria, Abuja, Nigeria and ICF Macro Calverton, Maryland, USA, 2009.

[9] E. P. Opare, Time Series Models for the Decrease in Under-Five Mortality, Thesis 
submitted to the Department of Mathematics, Kwame Nkrumah University of Science and Technology, Ghana, 2014.

[10] A. M. Starrs, Safe motherhood initiative: 20 years and counting, Lancet (London England) 368(9542) (2006), 1130-1132. https://doi.org/10.1016/S0140-6736(06)69385-9

[11] Levels and Trends in Child Mortality - United Nations Inter-Agency Group for Child Mortality Estimates UN-IGME, Report 2019.

[12] A. Usman, M. A. Sulaiman, I. Abubakar, Trends of neonatal mortality in Nigeria from 1990 to 2017 using time series analysis, J. Appl. Sci. Environ. Manage. 23(5) (2019), 865-869. https://doi.org/10.4314/jasem.v23i5.15

[13] World Health Organisation, Child Mortality: Millennium Development Goal (MDG) 4, The Partner for Maternal and New Born Birth, World Health Organisation, September 2011. http://www.who.int/pmnch/media/press_materials/fs/fs_mdg4_childmortality/en/

[14] S. Yaya, M. Ekholuenetale, G. Tudeme, S. Vaibhav, G. Bishwajit and B. Kadio, Prevalence and determinants of childhood mortality in Nigeria, BMC Public Health 17 (2017), 485. https://doi.org/10.1186/s12889-017-4420-7

\section{Donalben Onome Eke}

Department of Statistics, Faculty of Physical Sciences, University of Benin, Benin City, Edo State, Nigeria

e-mail: ekeonome@gmail.com

\section{Friday Ewere}

Department of Statistics, Faculty of Physical Sciences, University of Benin, Benin City, Edo State, Nigeria

e-mail: friday.ewere@uniben.edu

\footnotetext{
This is an open access article distributed under the terms of the Creative Commons Attribution License (http://creativecommons.org/licenses/by/4.0/), which permits unrestricted, use, distribution and reproduction in any medium, or format for any purpose, even commercially provided the work is properly cited..
} 